\title{
CORRIGENDUM
}

\section{Autologous olfactory mucosal transplant in chronic spinal cord injury: an Indian Pilot Study}

HS Chhabra, C Lima, S Sachdeva, A Mittal, V Nigam, D Chaturvedi, M Arora, A Aggarwal, R Kapur and TAH Khan

Spinal Cord (2009) 47, 904; doi:10.1038/sc.2009.109

Corrections to: Spinal Cord (2009) 47, 887-895; doi:10.1038/

sc.2009.54; published online 2 June 2009

The word 'olfactory' was not included in the title of the above referenced paper. The correct title is shown above.

The authors would like to apologize for this error. 